\title{
Wipe-out After Glaucoma Filtration Surgery
}

\author{
${ }^{1}$ Marlene R Moster, ${ }^{2}$ Augusto Azura-Blanco \\ ${ }^{1}$ The Glaucoma Service, Wills Eye Hospital, Jafferson Medical College, Philadelphia \\ ${ }^{2}$ The Department of Ophthalmology, Aberdeen royan Infirmary, University of Aberdeen, UK
}

The phenomenon of severe visual loss after surgery, with no obvious cause, is known as 'wipe-out' or 'snuff syndrome'. Wipe-out may affect patients who have very severe glaucomatous damage (Figs $1 \mathrm{~A}$ and $\mathrm{B}$ ), and overall is a very uncommon complication but remains an important concern among glaucoma surgeons.

Although, wipe-out was probably more common after fullthickness filtration surgery, ${ }^{1}$ it is not known whether patients who had been diagnosed with wipe out had other undetected causes such as macular edema, hypotonous maculopathy or inflammation. With modern surgical techniques this entity is becoming increasingly rare. ${ }^{2-4}$ In this review we will discuss the reported incidence of wipe-out, possible mechanisms, and how current practice is helping us to virtually eliminate this problem.

\section{Incidence and Risk Factors}

There are a few studies that have evaluated the incidence of wipe out after trabeculectomy. The reported incidence ranged from 0 to $0.95 \%$ of surgeries. ${ }^{5}$ A retrospective study of 508 trabeculectomies identified 4 cases of wipe-out, all of which had retrobulbar anaesthesia. ${ }^{5}$ Older patients with high preoperative IOP, advanced visual field defects affecting the central field, with split fixation, and postoperative complications would appear to be at increased risk.

\section{Possible Mechanisms and Prevention Strategies}

\section{Direct Damage to the Optic Nerve from Anesthetic Technique}

Glaucoma is a chronic condition characterized by progressive pressure/ischemic damage to the optic nerve head. ${ }^{6}$ Glaucoma patients with compromised optic nerves may be at futher risk of damage and possibly wipe-out from orbital retrobulbar and peribulbar anesthesia as there is potential for direct trauma, pressure on the nerve, and/or ischemia. Localized pressure to the optic nerve may result from a retrobulbar hematoma, a hematoma within the optic nerve sheath, or simply from the volume of anaesthetic injected. ${ }^{7}$ Even with a low volume of local anesthetic (LA) the injected fluid may become trapped between fascial layers yielding a 'compartment syndrome'.
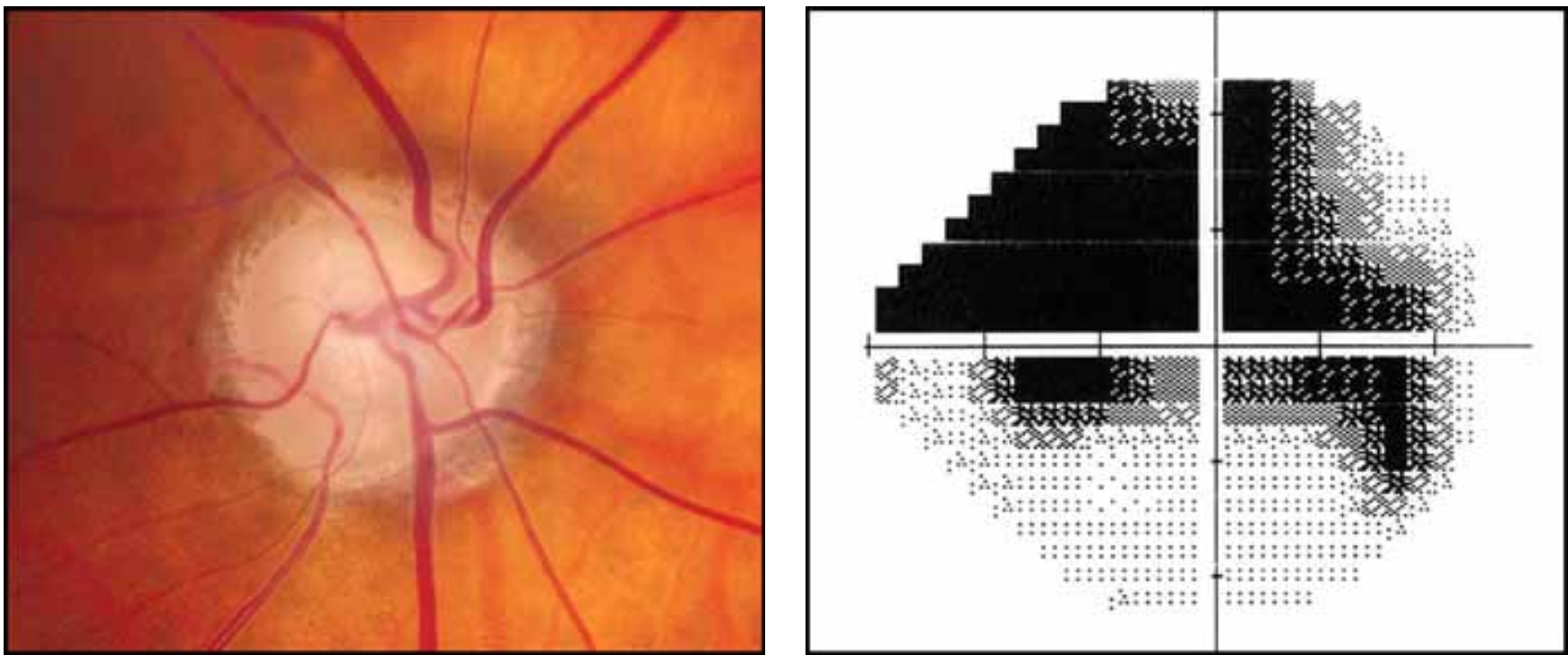

Figs 1A and B: Visual field and optic disc of a patient with very severe glaucomatous damage who might be susceptible to have wipe-out 
Localized pressure may also induce ischemia of the nerve, as may epinephrine (adrenaline) if used in the LA mixture. For patients whose optic nerve is already damaged by glaucoma, this could result in wipe-out. ${ }^{6,8}$

Additional indirect evidence of the possible effect of local anesthetic was noted in a small series of 3 cases of hyaluronidase-associated orbitopathy, in which the most severe and longlasting visual loss occurred in the one patient who had glaucoma. ${ }^{9}$ Doppler imaging studies have shown that retrobulbar injections can cause a marked reduction in blood flow in the arteries supplying the anterior optic nerve, particularly if epinephrine is included in the LA mixture. ${ }^{10,11}$ This effect is not seen with anterior placement of LA, for example by sub-conjunctival anesthesia. ${ }^{12}$

The problems described above could potentially occur with retrobulbar, peribulbar or posterior sub-Tenon's LA. Currently, a high index of suspicion for this event has made many glaucoma specialists alter their anesthesia technique in order to avoid injecting retro or peribulbar anesthesia for any surgery on glaucoma patients. ${ }^{13}$ Currently preferred techniques are anterior sub-Tenon's, sub-conjunctival, topical and intra-cameral anaesthesia. ${ }^{13}$ These 'newer' techniques appear to be successful in terms of safety and patient acceptability. ${ }^{6}$

\section{Pressure Spike}

Early undiagnosed postoperative IOP spikes could potentially inflict further insult to a very severely damaged optic nerve with end-stage glaucoma. Thus, it seems logical to associate an early and severe pressure spike with the occurrence of wipeout. Pressure spikes may occur if the scleral flap has been sutured too tightly or the fistula is blocked by iris tissue or a blood clot.

In patients with advanced glaucomatous damage undergoing trabeculectomy IOP should be monitored a few hours after surgery, and also the following day. Thus, if there is an early IOP spike it can be treated accordingly.

\section{Postoperative Hypotony}

Postoperative profound hypotony has been associated with "wipe-out", and it seems that this complication was more common when full-thickness filtration procedures were the standard surgeries for glaucoma. In the recent tube versus trabeculectomy study (TvT), choroidal effusion was an independent risk factor for unexplained visual acuity loss after surgery. ${ }^{14}$ Choroidal effusion is generally considered a relatively mild problem, but in the TvT study results suggested that this complication may not be always benign in nature. ${ }^{14}$

To prevent postoperative hypotony, intraoperative and postoperative control of outflow drainage is essential. During a glaucoma filtration procedure, the surgeon will try to provide sufficient outflow of aqueous thereby lowering the intraocular pressure (IOP) but avoiding complications, specifically hypotony, flat anterior chamber, choroidal detachment, and pressure spikes. Repeated injections of BSS through the paracentesis or use of an anterior chamber maintainer is recommended to test the outflow after initial suturing of the scleral flap. The flow can then be adjusted as needed.

The possibility of removing or cutting a scleral flap suture allows the surgeon to tightly close the scleral flap intraoperatively to decrease the probability of developing profound hypotony and a flat anterior chamber, especially if mitomycin-C has been used. Permanent and/or releasable scleral-flap sutures can be cut in the postoperative period to enhance the outflow.

Releasable sutures to close the scleral flap have practical advantages as the externalized suture can be easily removed and is effective in cases of a hemorrhagic or thickened bleb making suture-lysis difficult if not impossible. Additionally, the releasable sutures can be removed at the slit-lamp since laser equipment is not required. ${ }^{15-21}$ There are some potential disadvantages of releasable sutures, including some additional operating time, potential discomfort if they are not buried, and ocular infection. ${ }^{22,23}$ If antimetabolites are to be used there may be a risk of an aqueous leak around the suture site.

The timing for cutting/releasing sutures is important. If antimetabolites are not used, it should be done within the first two weeks. Later, fibrosis of the scleral flap may negate any potential increase in outflow. The window of opportunity is expanded when antimetabolites have been associated with the surgery, although the response decreases with a longer interval to suture release. ${ }^{24}$

Suture release/lysis should be performed in a conservative step-wise manner. Usually only one suture is released at a time to avoid the possible complications of overfiltration, hypotony, and shallow anterior chamber. After the suture is released, if the bleb and IOP were unchanged, ocular massage or focal pressure to the bleb can be applied. If unsuccessful, the surgeon may consider the possibility of releasing a second suture.

In summary, the wipeout syndrome is a rare yet possible consequence after glaucoma surgery in eyes with advanced disease. Precautions such as changes in anesthesia techniques, careful monitoring of perioperative IOP spikes and careful attention to avoid both high and low postoperative pressures will help make this entity a thing of the past.

\section{REFERENCES}

1. Sugar SH. The glaucomas, 2nd Edition. New York: Hoeber 1957;261.

2. Law SK, Nguyen AM, Coleman AL, Caprioli J. Severe loss of central vision in patients with advanced glaucoma undergoing trabeculectomy. Arch Ophthalmol 2007;125:1044-50.

3. Moster MR, Moster ML. Wipe-out: a complication of glaucoma surgery or a just a blast from the past. Am J Ophthalmol 2005; 140:705-6.

4. Moster MR, Azuara-Blanco A. Techniques of glaucoma filtration surgery. Focal Points module. American Academy of 
Ophthalmology, 1999.

5. Costa VP, Smith M, Spaeth GL, Gandham S, Markovitz B. Loss of visual acuity after trabeculectomy. Ophthalmology 1993;100:599-612.

6. Eke T. Anesthesia for glaucoma surgery. Ophthalmol Clin North Am, 2006;19:245-55.

7. Hamilton RC. Complications of ophthalmic regional anesthesia. In: Finucaine BT (Ed). Complications of regional anesthesia 1999 Churchill Livingstone, Philadelphia. P.39-55).

8. Henry JC. Snuff syndrome. J Glaucoma 1994; 3: 92-95.

9. Kumar CM, Dowd TC, Dodds C, Boyce R. Orbital swelling following peribulbar and sub-Tenon's anaesthesia. Eye 2004;18:418-420.

10. Hessemer V. [Anesthesia effects on ocular circulation. Synopsis of a study]. Fortschr Ophthalmol. 1991;88:577-587.

11. Hulbert MF, Yang YC, Pennefather PM, Moore JK. Pulsatile ocular blood flow and intraocular pressure during retrobulbar injection of lignocaine: influence of additives. J Glaucoma 1998;7:413-6.

12. Huber KK, Remky A. Effect of retrobulbar versus subconjunctival anaesthesia on retrobulbar haemodynamics. Br J Ophthalmol 2005;89:719-23.

13. Jones E, Clarke J, Khaw PT. Recent advances in trabeculectomy technique. Curr Opin Ophthalmol 2005;16:107-13.

14. Gedde SJ, Herndon LW, Brandt JD, et al. Surgical complications in the tube versus trabeculectomy study during the first year of follow up. Am J Opthalmol 2007;143:23-31.

15. Wilson RP. Technical advances in filtration surgery. In: McAllister JA, Wilson RP (Eds): Glaucoma. Boston, Butterworths, 1986;243-350.

16. Cohen JS, Osher RH. Releasable scleral flap suture. Ophthalmol Clinics of North America 1988;1:187-97.

17. Kolker AE, Kass MA, Rait JL. Trabeculectomy with releasable sutures. Arch Ophthalmol 1994;112:62-6.

18. Johnstone MA, Wellington DP, Ziel CJ. A releasable scleralflap tamponade suture for guarded filtration surgery. Arch
Ophthalmol 1993;111:398-403.

19. Maberley D, Apel A, Rootman DS. Releasable "U” suture for trabeculectomy surgery. Ophthalmic Surg 1994;25:251-5.

20. Raina UK, Tuli D. Trabeculectomy with releasable sutures: a prospective, randomized pilot study. Arch Ophthalmol 1998;116:1288-93.

21. Shin DH. Removable-suture closure of the lamellar scleral flap in trabeculectomy. Ann Ophthalmol 1987;19:51-3.

22. Burchfield JC, Kolker AE, Cook SG. Endophthalmitis following trabeculectomy with releasable sutures. Arch Ophthalmol 1996;114:766.

23. Rosemberg LF, Siegfried CJ. Endophthalmitis associated with a releasable suture. Arch Ophthalmol 1996;114:767.

24. Tezel G, Kolker AE, Kass MA, Wax MB. Late removal of releasable sutures after trabeculectomy or combined trabeculectomy with cataract extraction supplemented with antifibrotics. J Glaucoma 1998;7:75-81.

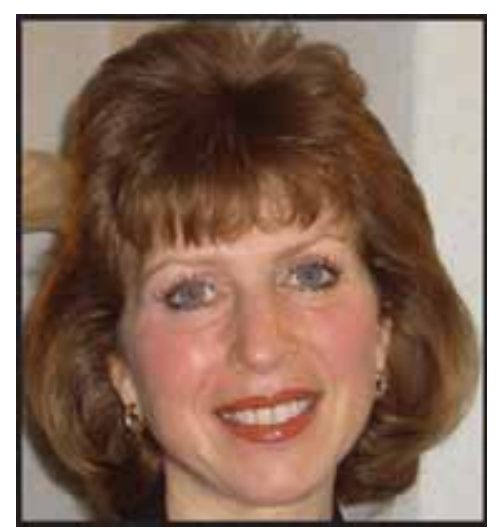

Dr Marlene R Moster (Marlenemoster@aol.com) 



\title{
Submitting a paper/video to Journal of Current Glaucoma Practice (Glaucoma Review Journal with DVD)
}

\begin{abstract}
INSTRUCTION TO AUTHORS
Journal of current glaucoma practice is a glaucoma review journal with video assisted teaching. It publishes invited review articles on basic and clinical sciences in Glaucoma and videos related to glaucoma diagnostics or surgery. Original research material can also be integrated into a review article. Articles should be submitted only by individuals with experience and expertise in the topic that they are reviewing. Videos can be submitted by any glaucoma specialist and may be incorporated into the journal DVD after peer review.

Before preparing a manuscript, the author should submit a detailed outline of the proposed article to the Editor-in-Chief to assure that the material is appropriate and that no similar article is in preparation. Please allow 2 to 4 weeks for a response.
\end{abstract}

Please do not hesitate to contact the Editorial Office if you have any questions.

\section{THE REVIEW}

Your review can be up to 2500 words in length and should highlight and discuss all interesting developments in the subject, as reflected in the recent literature. In addition to describing recent trends, you can give a sysnopsis of your own opinions of the topics discussed and suggest a preferred practice pattern.

\section{MANUSCRIPT FORMAT}

The review must be double-spaced and a maximum of 2500 words in length (excluding references).

\section{Review structure}

The review must contain the following:

Cover page: Stating the title, authors and their affiliations, and full contact details for the corresponding author (including phone number and e-mail address).

Introduction: This should be a paragraph of 50-100 words outlining the scope of the review and mentioning any earlier work which will place the review in context.

Text of review: Includes headings and titled paragraphs to subdivide the text. Ensure that at least one sentence divides each heading (i.e. do not have a subheading directly beneath a full heading).

Conclusion: A paragraph of 50-100 words drawing together the implications of the review topic and, if appropriate, giving suggestions for future research.

Acknowledgements: Of professional colleagues and funding bodies only.

Reference section: References should be in numerical sequence (Vancouver style), include the first three authors, or all authors if there are six or fewer.

Figure titles and legends: Must be provided for all figures

Figures and tables: Must be cited in text.

Figures and tables must be

Original whenever possible

Clearly marked as "original" or "previously published" upon submission

Accompanied by full source details when not original

Figures should not be embedded within the text but should be submitted as separate files. Figure legends should be included in the main body of the text following the references.

References cited in figures or tables must be numbered in sequence, according to the position of the first text citation of the figure or table.

\section{Illustrations}

Original ideas for explanatory diagrams are welcomed. Electronic artwork should be submitted in JPEG, TIFF, EPS or PPT formats. Please state clearly whether figures/tables have been published previously.

Color figures: There is a no charge to authors if you wish your figures to be produced in color. 


\section{DISCLOSURES}

Authors should include all relevant information regarding Conflict of Interest and Sponsorship Statements.

\section{SUBMITTING YOUR PAPER}

Manuscripts should be submitted by e-mail at currentglaucomapractice@gmail.com

If you have any query or suggestion, please do not hesitate to contact:

Editor-in Chief

Tanuj Dada, MD, Dr Rajendra Prasad Centre for Ophthalmic Sciences, All India Institute of Medical Sciences, New Delhi, India e-mail: tanujdada@hotmail.com

The manuscript file should include the text, references, structured abstract, keywords, figure legends and author address. Figures and tables should be submitted as separate files.

References cited in figures or tables must be numbered in sequence, according to the position of the first text citation of the figure or table. Unpublished data, submitted manuscripts and personal communications must be referenced in the text only as follows:

Personal communication: (Author A, personal communication).

Submitted paper: (Author A, Author B, unpublished data).

You are responsible for the accuracy of the references and for obtaining permission to use personal communications.

\section{REFERENCE FORMAT}

In the text, reference citations should be typed in superscript.

Please list the first three authors for each reference and then et al, unless there are six authors or fewer, in which case all authors should be listed. Provide full reference details (author(s), title, journal, year, volume, pages).

Journal names should be abbreviated as in the Index Medicus.

References should be structured as follows:

Journal:

Author A, Author B, Author C. Title of the paper. Journal Abbreviation 2000; 4:25-27.

With annotation describing importance of reference, if bulleted

Book:

Author A, Author B, Author C. Title of the book section. In: Book name. Edition number. Edited by Editor A, Editor B, Editor C (editors). Location of Publisher: Publisher; 2000. pp. 25-27.

Copyright transfer form with article title and signature of all authors needs to be mailed or faxed during submission of the article.

\section{SUBMISSION OF VIDEOS}

The journal accepts videos demonstrating surgical techniques and newer diagnostic techniques. Videos for the CD/DVD should be edited with an audio commentary or a text overlay and submitted in the following formats: .mpg/.wmv/.dat The CD/DVD with video may be directly sent to the journal editorial office (address given below).

Video should be accompanied by

Cover page: stating the title, authors and their affiliations, and full contact details for the corresponding author (including phone number and email address).

A small summary of the procedure being shown in about 150 words should be included.

Video should be accompanied by a moving legend describing the procedure with or without an audio in English language.

ADDRESS OF THE JOURNAL OFFICE FOR SUBMISSION OF VCD OR DVD VIDEOS:

Jaypee Brothers Medical Publishers Pvt. Ltd. 23/23B EMCA House, Ansari Road, Daryaganj, New Delhi, India

Phones: +91-11-23272143, +91-11-23272703, +91-11-23282021, +91-11-23245672

Rel: 32558559 Fax: +91-11-23276490, +91-11-23245683

e-mail: jaypee@jaypeebrothers.com 


\section{SUBSCRIPTION INFORMATION}

Annual subscription:

Individual: Rs. 1600.00

$\$ 130.00$

£ 75.00

Institutional: Rs. 3000.00

$\$ 160.00$

£ 100.00 (national)

(international)

(international)

(national)

(international)

(international)
Subscription can be sent to

$\mathrm{M} / \mathrm{s}$ Jaypee Brothers Medical Publishers (P) Ltd

Journals Department

G-7, 23/23B, EMCA House, Ansari Road

Daryaganj, New Delhi 110 002, India

Phones:+91-11-23272143, +91-11-23272703,

+91-11-23282021, +91-11-23245672

Fax: $\quad+91-11-23276490,+91-11-23245683$

This journal is published thrice in a year, i.e. January, May and September, every year. Dollar rates apply to subscribers in all the countries except the UK and the Republic of Ireland where the pound/sterling price applies. All subscriptions are payable in advance and all the rates include postage. Journals are sent by air to all the countries except Indian subcontinent. Subscriptions are on an annual basis, i.e. from January to December. Payment will be made by sterling cheque, dollar cheque, credit card or directly through our bank account at the following address:
1. Our banker's name:
Canara Bank, Netaji Subhash Marg
Darya Ganj, New Delhi 110002
2. Telephone No:
011-23273015, 011-23273849
3. Fax No:
4. Telex Number:
011-23255606
5. Our Current A/c No:
3166291
6. Amount to be transferred
3828 in the name of:
JAYPEE BROTHERS MEDICAL
7. Swift code No:
PUBLISHERS (P) LTD., NEW DELHI
CNRB IN BB DFM

For further queries please do not hesitate to contact MR TARUN DUNEJA at e-mail: t_duneja@rediffmail.com

\section{ADVERTISEMENT RATES \\ (For the Print Issues) \\ Page \\ Back cover-colour Inside front cover-colour \\ Inside back cover-colour \\ Special position*-colour \\ Inside full page-colour

\begin{tabular}{l} 
Single \\
\hline Rs. 25,000 \\
Rs. 20,000 \\
Rs. 15,000 \\
Rs. 12,500 \\
Rs. 10,000
\end{tabular}

*First page, page facing editorial board, page facing table of contents.

Cover page advertisements not available for a single issue.

Technical Details

Paper size

Print size

Digital file format

Printed on art paper using offset printing.

Schedule

Issues are published in the months of January, May and September.

Advertisement material along with purchase order and payment should reach us at least four weeks prior to the scheduled print date.

Payment Details

- Payment should favour "Jaypee Brothers Medical Publishers Pvt (Ltd)" and should be payable at New Delhi, India.

- Payment to be done at the time of submitting the advertisement material/booking the advertisement. Please send your advertisement request, payment and advertisement material to the address given above. Editorial board reserves the right to accept or decline the advertisement. 